\title{
The Term Structure of Interest Rates and INFLATION ForeCAST TARGETING
}

\author{
Eric Schaling \\ South African Reserve Bank Chair, University of Pretoria, Centre for Dynamic Macroeconomic \\ Analysis, University of St Andrews, Scotland, UK and CentER Tilburg University \\ Willem Verhagen \\ ING Investment Management, The Hague \\ Sylvester Eijffinger \\ CentER Tilburg University, RSM Erasmus University, CESifo and CEPR
}

\begin{abstract}
This paper examines the implications of the expectations theory of the term structure of interest rates for the implementation of inflation targeting. We show that the responsiveness of the central bank's instrument to the underlying state of the economy is increasing in the duration of the long-term bond. On the other hand, an increase in duration will make long-term inflationary expectations - and therefore also the long-term nominal interest rate - less responsive to the state of the economy. The extent to which the central bank is concerned with output stabilisation will exert a moderating influence on the central bank's response to leading indicators of future inflation. However, the effect of an increase in this parameter on the long-term nominal interest rate turns out to be ambiguous. Next, we show that both the sensitivity of the nominal term spread to economic fundamentals and the extent to which the spread predicts future output, are increasing in the duration of the long bond and the degree of structural output persistence. However, if the central bank becomes relatively less concerned about inflation stabilisation the term spread will be less successful in predicting real economic activity.
\end{abstract}

Keywords: term structure of interest rates, inflation targets, optimal monetary policy, dynamic programming

JEL E43, 52, 58

\section{1}

\section{Introduction}

Since the early 1990s the conduct of monetary policy in many countries has switched to a regime of direct inflation targeting. This change was triggered either as a result of the breakdown of the relationship between money growth rates and inflation (New Zealand and Canada) or because of the disappointment following the use of exchange rates as an intermediate target (United Kingdom, Sweden and Finland). ${ }^{1}$

In practice central banks can only affect inflation imperfectly and after a considerable time lag. Virtually all central banks implement monetary policy by setting the price at which the banking system's systematic shortage of central bank balances on the interbank money market will be relieved. ${ }^{2}$ This gives the central bank near-perfect and instantaneous control over the day-to-day interbank interest rate. From a theoretical perspective this raises the issue as to how explicit inflation targets should be translated into monetary policy instruments. For an analysis in the context of a New Keynesian DSGE model see Woodford (2003).

A seminal contribution to this question was made by Svensson (1997a) who has shown that, 
because of lags in the transmission process, inflation targeting implies inflation forecast targeting. In Svensson's analysis the inflation forecast produced by the central bank's structural model of the economy ${ }^{3}$ becomes an ideal intermediate target since it is by definition closely related to the ultimate policy goal and since it can be perfectly controlled by the central bank. Furthermore, the inflation forecast will lead to an optimal monetary policy rule which has the same form as the Taylor rule (Taylor, 1993). ${ }^{4}$

Also, the past few years have seen a revival of interest in the importance of the termstructure of interest rates for the transmission of monetary policy. When short-term inflationary expectations are given, a particular level of the central bank's key nominal interest rate will pin down the short-term real interest rate. According to the expectations hypothesis of the term structure (Shiller, 1979), the current short-term real rate and market expectations concerning future short-term real rates then determine the long real rate. This long-term real rate term will, in turn, affect the determinants of aggregate demand.

Earlier research on the term structure has focussed on explanations for the failure of the predictive content of long-short spread for future movements in interest rates (McCallum, 1994 and Rudebusch, 1995) and on the interaction between the term structure and shifts in the conduct of monetary policy in VAR-models (Fuhrer \& Moore, 1995 and Fuhrer, 1996).

Recent theoretical research on the term structure (see e.g., McGough et al., 2005) has focussed on analysing indeterminacy of rational expectations equilibria in the context of New Keynesian models. Tesfaselassie, Schaling and Eijffinger (2006) also incorporate the term structure of interest rates in the New Keynesian model. They find that under flexible inflation targeting and uncertainty in the degree of persistence in the economy, allowing for active learning possibilities has effects on the optimal interest rate rule followed by the central bank. In addition, there is an empirical literature (see e.g. Joyce, Lildholdt \& Sorensen, 2009) that analyses the nominal and real interest rate term structures over the period that the central bank has pursued an explicit inflation target. Then inflation risk premia and longer-term inflation expectations are inferred and analysed.

The purpose of this paper is to incorporate the term structure of interest rates into a traditional Keynesian model (TKM), namely the Svensson (1997a) inflation forecast targeting framework. To this end, Section 2 presents a model in which monetary policy affects the real economy via the term structure. In Section 3 we derive the central bank's optimal monetary policy rule. We show that the optimal short-term interest rate will be more responsive to the underlying state of the economy as the maturity of the long-term bond - measured by its duration - increases. Next, in Section 4 we discuss the implications of inflation forecast targeting for the long-term real interest rate and the long-term expected inflation rate. We show that the long-term nominal interest rate will be less responsive to the current state of the economy as a result of an increase in duration. Moreover, the effect of the relative weight on output stabilisation on the responsiveness of the long-term nominal interest rate turns out to be ambiguous. Finally, in Section 5 we examine the implications of inflation forecast targeting for the spread between short- and long-term interest rates. In particular, the optimal conduct of monetary policy will induce a positive relationship between the nominal term spread and future output. It is shown that this relationship will become stronger if either the duration of the long bond increases or if the relative weight on output stabilisation decreases. Section 6 concludes.

\section{2 \\ Monetary policy and the term structure}

The purpose of this section is to incorporate the term-structure of interest rates in the Svensson (1997a) inflation forecast targeting framework. To this end, we assume that the short-term nominal interest rate $\left(i_{t}\right)$ and the long-term nominal interest rate $\left(\mathrm{I}_{t}\right)$, are related by the following version of the Pure Expectations Hypothesis (PEH):

$I_{t}=(1-k) \sum_{\tau=t}^{\infty} k^{\tau-t} E_{t} i_{\tau} ; k \equiv \frac{D}{1+D}$ 
Here $I_{t}$ represents the nominal yield to maturity on a bond with maturity $\mathrm{m}(>1)$ while $\mathrm{i}_{\mathrm{t}}$ denotes the nominal yield on a one period bond which is traded on the interbank money market. This means that $i_{t}$ is under perfect control of the central bank and can therefore be seen as the instrument of monetary policy.

Shiller, Campbell and Schoeholtz (1983) have shown that any finite maturity bond can be approximated by an infinite maturity consol bond provided the (geometric) weights ensure that the duration of the consol is equal to the duration of the finite maturity bond. Assuming the duration of the long bond is constant and equal to $\mathrm{D}$ yields the linear approximation in equation (2.1). ${ }^{5}$ An increase in duration will cause the weighting pattern to decline less rapidly, and so the long-term interest rate will to a greater extent be determined by expected future short-term interest rates.

For our purposes it turns out to be convenient to rewrite (2.1) in its equivalent first-order form:

$$
I_{t}=(1-k) i_{t}+k E_{t} I_{t+1}
$$

Note that the long and short real interest rates will be equal if the parameter $k$ is equal to zero. In that case the model will collapse into the original Svensson (1997a) model in which there is no distinction between short and long-term interest rates.

Following the well-known Fisher decomposition, the short-term nominal rate can be written as the sum of the short-term real interest rate $\left(r_{t}\right)$ and expected inflation in the next period (conditional on the information available in period $\left.t\left(E_{t} \pi_{t+1}\right)\right)$ :

$i_{t}=r_{t}+E_{t} \pi_{t+1}$

Plugging equation (2.3) into (2.1) and rearranging we can decompose the long-term nominal rate into a long term real interest rate $\left(\mathrm{R}_{t}\right)$ and a long-term expected inflation rate conditional to the information available in the current period $\left(\prod_{t}^{e}\right)$ :

$I_{t}=R_{t}+\prod_{t}^{e} ; R_{t}=(1-k) \sum_{\tau=t}^{\infty} k^{\tau-t} E_{t} r_{\tau}$

$\prod_{t}^{e}=(1-k) \sum_{\tau=t}^{\infty} k^{\tau-t} E_{t} \pi_{\tau+1}$
Following Svensson (1997a) we assume that inflation and output are linked by the following short-term Phillips-curve relationship:

$\pi_{t+1}=\pi_{t}+\alpha_{1} y_{t}$

where $\pi_{t} \equiv p_{t}-p_{t-1}$, the inflation rate in period $t$ ( $p_{t}$ is the (log of the) price level). The variable $y_{t}$ represents the (log of the) output gap in period $t$ (where potential output has been normalised to zero). Finally, the parameter $\alpha_{1}$ measures the slope of the Phillips-curve. The output gap is determined by the following dynamic relationship:

$y_{t+1}=\beta_{1} y_{t}-R_{t}+x_{t+1}$

Following Svensson (1997a) we assume that output is serially correlated $\left(0 \leq \beta_{1}<1\right)$. Whereas in the Svensson model output is decreasing in the short-term real interest rate (with a lag of one period), we assume that next period's output gap is decreasing in the longterm real interest rate $\left(R_{t}\right)$. This assumption can be justified on the grounds that the interest rate sensitive components of aggregate demand generally do not depend directly on the day-today interbank money market interest rate, but rather on the yield of some financial asset with a longer maturity. ${ }^{7}$ For simplicity we assume that there is only one long-term interest rate in the output equation. Finally, output is increasing in an exogenous demand shock $\left(x_{t+1}\right)$ which is also serially correlated and stationary $\left(0 \leq \beta_{2}<1\right)$ :

$y_{t+1}=\beta_{1} y_{t}-R_{t}+x_{t+1}$

Having described the structure of the economy the preferences of the central bank remain to be specified. Monetary policy is conducted by a central bank with an explicit inflation target $\pi^{*}$ which aims to minimise deviations of inflation from this assigned target, on the one hand, and fluctuations of output around the natural rate (which is normalised to zero), on the other. ${ }^{8}$ Consequently, the central bank will choose a sequence of current and future short-term nominal rates to minimise the following loss function:

$L^{C B}=E_{t} \sum_{\tau=t}^{\infty} \delta^{\tau-t}\left[\frac{1}{2}\left(\pi_{\tau} \pi^{*}\right)^{2}+\frac{\lambda}{2} y_{\tau}^{2}\right]$ 
Here $\lambda$ represents the central bank's relative weight on output stabilisation while the parameter $\delta$ (which fulfils $0<\delta<1$ ) denotes the discount factor (i.e. a measure of the policy horizon). The expectation is conditional on the central bank's information set in period $t$ which contains current output $\left(y_{t}\right)$ the current inflation rate $\left(\pi_{t}\right)$ and the structure of the economy as described by equations $(2.3)-(2.7)$.

\section{3}

\section{Derivation of the optimal monetary policy rule}

Following Svensson (1997a), the model can be solved by dynamic programming. ${ }^{9}$ In this respect, next period's conditional expectation for output $\left(\mathrm{E}_{\mathrm{t}} \mathrm{y}_{\mathrm{t}+1}\right)$ can be regarded as an indirect control variable for the central bank. First of all, since next period's expected rate of inflation is predetermined by the Phillips curve (2.5), perfect control over the short-term nominal interest rate $\left(i_{t}\right)$ implies perfect control over the longterm real interest rate $\left(r_{t}\right)$. Next, by assumption the central bank is committed to the (timeinvariant) loss function specified in equation
(2.8), and economic agents face no uncertainty about the parameters of this loss function. This means that the central bank's plan for future instrument levels is fully credible in the sense that there is no discrepancy between the central bank's planned path of future short-term interest rates (conditional on all information available today) and the public's perception of this plan. In other words, all expected future short-term real interest rates (i.e. $\left.E_{t} r_{t+j}, j=1,2, \ldots\right)$ will be unambiguously pinned down by the expectation that in every future period the central bank will implement monetary policy so as to minimise its loss function. ${ }^{10}$

Consequently, for the central bank it only remains to set the current short real rate $\left(r_{t}\right)$, so as to attain that specific value of the current long real rate $\left(R_{t}\right)$ which is optimal from the point of view of minimising its loss function. Hence, in a fully credible inflation targeting regime the central bank will be able to control the long-term real interest rate perfectly. ${ }^{11}$ From the dynamic output equation (2.6) it can be seen that this implies perfect control over $\mathrm{E}_{\mathrm{t}} \mathrm{y}_{\mathrm{t}+1}$. The result is that, as in Svensson (1997a) the central bank's problem can be reformulated as follows:

$$
V\left(E_{t} \pi_{t+1}\right)=\underset{E_{t} y_{t+1}}{\operatorname{Min}}\left\{\left[\frac{1}{2}\left(E_{t} \pi_{t+1}-\pi^{*}\right)^{2}+\frac{\lambda}{2}\left(E_{t} y_{t+1}\right)^{2}\right]+\delta E_{t} V\left(E_{t+1} \pi_{t+2}\right)\right\}
$$

subject to

$E_{t+1} \pi_{t+2}=\pi_{t+1}+\alpha_{1} y_{t+1}$

As shown in Appendix A, the first-order condition for the minimisation problem in equation (3.1) will yield a rule for the central bank's conditional one-to-two year inflation forecast $\left(E_{t} \pi_{t+2}\right)$. This conditional inflation forecast thus becomes the central bank's intermediate target for monetary policy and can be expressed as follows:

$$
\begin{aligned}
& E_{t} \pi_{t+2}=\pi^{*}+n\left[E \pi_{t+1}-\pi^{*}\right] ; \\
& n \equiv \frac{\lambda}{\delta \alpha_{1}^{2} \mu+\lambda}
\end{aligned}
$$

The reduced-form parameter $\mu$ is a function of the parameters $\alpha_{1}, \delta$ and $\lambda$ (see Appendix A). If the central bank engages in strict inflation targeting (i.e. if the relative weight on output stabilisation $(\lambda)$ is equal to zero), it will set its intermediate target equal to the inflation target. However in the more realistic case of flexible inflation targeting, it will allow $E_{t} \pi_{t+2}$ to adjust gradually towards the assigned inflation target $\pi^{*}$. The speed of adjustment will then depend negatively on the central bank's relative weight on output stabilisation (i.e. $\partial \mathrm{n} / \partial \lambda>0$, see Appendix A).

From equations (2.5) and (2.6) it can be seen that the actual one-to-two year inflation forecast implied by the structure of the economy will be equal to:

$E_{t} \pi_{t+2}=\pi_{t}+\alpha_{1}\left(1+\beta_{1}\right) y_{t}-\alpha_{1} R_{t}+\alpha_{1} \beta_{2} x_{t}$ 
In Appendix B we compute an expression for $\mathrm{R}_{t}$, which is based on the assumption that the central bank seeks to attain the optimal intermediate target in each and every period (i.e. (3.2) holds for all $\tau \geq t$ ). Substituting this expression into (3.3) we obtain an equation for the actual one-to-two year inflation forecast in terms of period $t$ state variables and the central bank's instrument:

$$
\begin{aligned}
E_{t} \pi_{t+2}= & {\left[1+\frac{\alpha_{1}(1-k)}{\left(1+k \beta_{1}\right)}\right] \pi_{t}-\frac{k n(1-n)}{\left(1+k \beta_{1}\right)}\left(\pi_{t}-\pi^{*}\right)+\frac{\alpha_{1} \beta_{2}\left(1-k \beta_{2}\right)}{\left(1+k \beta_{1}\right)} x_{t} } \\
& +\frac{\alpha_{1}}{\left(1+k \beta_{1}\right)}\left[\left(1+\beta_{1}\right)\left(1+k \beta_{1}\right)+\alpha_{1}(1-k)-k\left(n(1-n)+\beta_{1}^{2}\right)\right] y_{t}-\frac{\alpha_{1}(1-k)}{\left(1+k \beta_{1}\right)} i_{t}
\end{aligned}
$$

Obviously, the central bank will choose $i_{t}$ such that the one-to-two year conditional inflation forecast in equation (3.4) will be equal to the optimal intermediate target specified in equation (3.2). Hence, by combining these two equations we find the following optimal monetary policy rule which expresses the optimal shortterm nominal interest rate as a function of all variables that characterise the current state of the economy (henceforth to be referred to as economic fundamentals):

$$
\begin{aligned}
i_{t}= & \pi^{*}+\left[1+\frac{(1-n)}{\alpha_{1}(1-k)}\left(1+k \beta_{1}-k n\right)\right]\left(\pi_{t}-\pi^{*}\right)+ \\
& \frac{\left(1+\beta_{1}-n\right)\left(1+k \beta_{1}\right)+\alpha_{1}(1-k)-k\left(n(1-n)+\beta_{1}^{2}\right)}{(1-k)} y_{t}+\frac{\beta_{2}\left(1-k \beta_{2}\right)}{(1-k)} x_{t}
\end{aligned}
$$

This equation has the same form as the Taylor rule and explicitly allows for an effect of the term structure of interest rates on the optimal short-term interest rate (see PROPOSITION 1 below) ${ }^{12}$ Note that this endogenous interest rate rule will collapse into the Svensson rule if the output gap is directly determined by the central bank's instrument (i.e. if $\mathrm{k}=0){ }^{13}$

Using equation (2.3) and the fact that $E_{t} \pi_{t+1}$ $=\pi_{t}+\alpha_{1} y_{t}$, the optimal (ex ante) short-term real rate will be:

$$
\begin{aligned}
r_{t}= & \frac{(1-n)}{\alpha_{1}(1-k)}\left(1+k \beta_{1}-k n\right)\left(\pi_{t}-\pi^{*}\right)+ \\
& \frac{\left(1+\beta_{1}-n\right)\left(1+k \beta_{1}\right)-k\left(n(1-n)+\beta_{1}^{2}\right)}{(1-k)} y_{t}+\frac{\beta_{2}\left(1-k \beta_{2}\right)}{(1-k)} x_{t}
\end{aligned}
$$

The effect of several parameters on the extent to which both the short-term nominal and short-term real interest rate will respond to the indicator - or fundamental - variables can be summarised by the following proposition:

PROPOSITION 1: The responsiveness of the short-term interest rate (either nominal $\left(i_{t}\right)$ or real $\left.\left(r_{t}\right)\right)$ to economic fundamentals will increase if:

1. the duration of the long-term bond (D) increases

2. the relative weight on output stabilisation $(\lambda)$ decreases

3. the degree of output persistence $\left(\beta_{1}\right)$ increases

\section{Proof: see Appendix E}

The first part of PROPOSITION 1 summarises the effect of the term structure on the central bank's optimal reaction function. The shortterm interest rate will respond more strongly to economic fundamentals if the lifetime of the long-term bond increases. This is due to a decrease in policy leverage over the long-term interest rate as the latter will now to a greater extent be determined by expected future short rates. However, since central bank preferences are constant over time, a change in duration will not alter the central bank's optimal intermediate target as expressed in equation (3.2). Therefore, the central bank will have to manipulate its 
short-term interest rate more actively in order to attain the same desired effect on the long-term real interest rate.

The second part of this proposition is equivalent to Svensson's finding that the extent to which the central bank's instrument will respond to the current state of the economy will decrease as the central bank is more concerned with short-term output stabilisation. The assumption is that this will reduce the speed with which the central bank plans to return inflation to its target after the economy has been hit by a shock. Hence, the short-term interest rate will respond less strongly to the current economic situation. This result is insensitive to the question whether or not the term structure of interest rates constitutes an important part of the monetary transmission mechanism.

$R_{t}=\frac{(1-n)}{\alpha_{1}}\left(\pi_{t}-\pi^{*}\right)+\left(1+\beta_{1}-n\right) y_{t}+\beta_{2} x_{t}$

PROPOSITION 2: The optimal long-term real interest rate $\left(R_{t}\right)$ will be more responsive to economic fundamentals if:

1. the relative weight on output stabilisation $(\lambda)$ decreases

2. the degree of output persistence $\left(\beta_{1}\right)$ increases

The proof follows immediately from equation (4.1) where we realise that $\partial \mathrm{n} / \partial \lambda>0$. The assumption is that in our model the long term real interest rate is exactly the same as the optimal ex ante real short term interest rate $\left(i_{t}-\alpha_{1} y_{t}-\pi_{t}\right)$ obtained in the model where the

$\prod_{t}^{e}=\pi^{*}+\frac{(1-k)}{(1-k n)}\left(\pi_{t}-\pi^{*}\right)+\frac{\alpha_{1}(1-k)}{(1-k n)} y_{t}$

From this expression we can infer the following proposition for the extent to which long-term inflationary expectations will react to changes in the underlying state of the economy:

PROPOSITION 3: The long-term expected rate of inflation $\left(\prod_{t}^{e}\right)$ will be more responsive to economic fundamentals if:

1. the duration of the long-term bond (D) decreases
Finally, an increase in output persistence $\left(\beta_{1}\right)$ will increase the effect of current exogenous shocks $\left(x_{t}\right)$ on next period's output gap $\left(y_{t+1}\right)$. To offset this effect, interest rates will have to be manipulated more actively if the central bank is to attain its objectives for output and inflation stabilisation.

\section{4}

\section{Implications for the long-term interest rate}

This section will examine the implications of the optimal monetary policy rule (3.5) for the long real rate $\left(\mathrm{R}_{t}\right)$ and the long term expected inflation rate $\left(\prod^{e}\right)$, that is for the inflation term structure (herafter ITS). First of all, substituting equation (3.6) into the expression for $\mathrm{R}_{t}$ obtained in Appendix B we can derive:

term structure is absent (i.e. if $k=0$ ). This result should not be surprising, since in both models the central bank seeks to attain the same value for $\mathrm{E}_{t} \pi_{t+2}$ (which implies that in both models $\mathrm{E}_{t} \mathrm{y}_{t+1}$ will be the same). The only difference is that $\mathrm{E}_{t} \mathrm{y}_{t+1}$ will be directly influenced by $i_{t}$ in the absence of the term structure, while in our model the central bank will set it such as to attain that specific value of $\mathrm{R}_{t}$ consistent with its intermediate target.

In Appendix $\mathrm{C}$ it is shown that, under the optimal rule, long-term expected inflation - or the inflation term structure - will be determined as follows:

2. the relative weight on output stabilisation $(\lambda)$ increases

\section{Proof: see Appendix E}

An increase in the lifetime of the long-term bond as measured by its duration will cause the rate of inflation expected to prevail over the lifetime of this bond to be less sensitive to current economic fundamentals. This is because expected (one period) inflation rates 
in the distant future will exert more influence on the long-term expected rate of inflation. For a given expected path of future inflation rates as given by the central bank's optimal target rule (3.2) this will cause the long-term expected rate of inflation to be more stable over time. Next, an increase in the relative weight on output stabilisation will decrease the speed with which the central bank will bring the conditional inflation forecast back in line with the assigned target. As a result, current shocks will to a greater extent penetrate into expected future one period inflation rates and consequently into the long-term expected inflation rate.

Finally, using equation (2.4) we can express the long nominal interest rate as the sum of equation (4.1) and (4.2):

$I_{t}=\pi^{*}+\frac{\alpha_{1}(1-k)+(1-n)(1-k n)}{\alpha_{1}(1-k n)}\left(\pi_{t}-\pi^{*}\right)+\frac{\alpha_{1}(1-k)+(1-k n)\left(1+\beta_{1}-n\right)}{(1-k n)} y_{t}+\beta_{2} x_{t}$

Using the results obtained in Propositions 2 and 3 we can summarise the effect of several parameters on the responsiveness of the long- term nominal interest rate to economic fundamentals in the following table:

Table 1

Effect of several parameters on the sensitivity of the long nominal rate to economic fundamentals

\begin{tabular}{|c|c|c|c|}
\hline & $\mathbf{R}_{t}$ & $\prod_{t}^{e}$ & $\mathbf{I}_{t}$ \\
\hline $\mathrm{D}$ & 0 & $<0$ & $<0$ \\
\hline$\lambda$ & $<0$ & $>0$ & $?$ \\
\hline$\beta_{1}$ & $>0$ & 0 & $>0$ \\
\hline
\end{tabular}

This table presents the sign of the partial derivative of the variables listed in the first row with respect to the parameters in the first column. First of all, an increase in the duration of the long-term bond will induce the long-term nominal rate to be less sensitive to economic fundamentals. Consequently, while an increase in duration will elicit a more vigorous instrument response, this increase in central bank activism will impart a greater degree of stability to the interest rate which affects aggregate demand. Under a fully credible inflation targeting regime (i.e. a regime in which there is no uncertainty about the objectives of the central bank) this effect is entirely induced through the effect on long-term inflationary expectations (the inflation term structure).

Next, the effect of an increase in the relative weight on output stabilisation $(\lambda)$ on the longterm nominal rate turns out to be ambiguous. On the one hand, a greater concern for output stabilisation will lead the central bank to eliminate the effect of an inflationary shock more gradually which will translate into a less vigorous response of both the current and future expected real short rates to the state of the economy. On the other hand, this decrease in activism will lead to an enhanced effect of this shock on future expected inflation rates which will increase the expected inflation component in the long-term nominal rate.

Finally, the effect of an increase in degree of output persistence $\left(\beta_{1}\right)$ works entirely through the induced increased responsiveness of current and expected future short real rates.

\section{5}

\section{The behaviour of the term spread under the optimal rule}

This section will look at the implication of an inflation targeting regime for the spread between long and short-term interest rates. The real term spread can be computed by subtracting equation (3.6) from equation (4.1). 
For simplicity we will assume that there is no persistence in the exogenous demand shock (i.e. $\beta_{2}=0$ ):

$R_{t}-r_{t}=-\frac{k(1-n)\left(1+\beta_{1}-n\right)}{\alpha_{1}(1-k)}\left(\pi_{t}-\pi^{*}\right)-\frac{k\left(1+2 \beta+n\left[n-\left(2+\beta_{1}\right)\right]\right)}{(1-k)} y_{t}$

Next, the inflation term spread can be found by subtracting $\mathrm{E}_{t} \pi_{t+1}=\pi_{t}+\alpha_{1} \mathrm{y}_{t}$ from equation (4.3):

$$
\prod_{t}^{e}-\mathrm{E}_{t} \pi_{t+1}=-\frac{k(1-n)}{(1-k n)}\left(\pi_{t}-\pi^{*}\right)-\frac{\alpha_{1} k(1-n)}{(1-k n)} y_{t}
$$

Of course, the nominal term spread is now simply the sum of equations (5.1) and (5.2) so we have: $\mathrm{I}_{t}-\mathrm{i}_{t}=\mathrm{R}_{t}-\mathrm{r}_{t}+\prod_{t}^{e}-\mathrm{E}_{t} \pi_{t+1}$.

The effect of the underlying cyclical position of the economy on the term structure can be summarised by the following proposition:

PROPOSITION 4: If the economy experiences a boom, i.e. if $\pi_{t}>\pi^{*}$ and $\mathrm{y}_{t}>0$, the real term spread, the inflation term spread and therefore also the nominal term spread will be inverted, i.e. it will hold that: $\mathrm{R}_{t}-\mathrm{r}_{t}<0, \prod_{t}^{e}-\mathrm{E}_{t} \pi_{t+1}<0$ and $\mathrm{I}_{t}-\mathrm{i}_{t}<0$ respectively.

\section{Proof: see Appendix E}

If the current rate of inflation exceeds the target and if the output gap is positive there will be an increase in the future rate of inflation. The central bank will not allow inflation to deviate systematically from its target and, therefore, output will not systematically differ from potential. If the central bank is concerned with output stabilisation (i.e. if $\lambda>0$ ) the optimal target rule (3.2) implies that the central bank will disinflate the economy gradually. Consequently, expected future short-term real rates will decline gradually towards zero and expected future inflation rates will decline gradually towards the assigned inflation target. ${ }^{14}$

Since the long-term real rate is a weighted average of expected future real short rates and since the long-term inflation rate is a weighted average of expected future one-period inflation rates, both the real and the inflation term structure will be inverted as a result of optimal monetary policy.

Furthermore, this will induce a positive relationship between both the real and the inflation term spread in period $t$ and the output gap in period $t+1$. Formally this can be inferred from the expression for $\operatorname{Cov}\left[\left(\mathrm{I}_{t}-\mathrm{i}_{t}\right) \mathrm{y}_{t+1}\right]$ $=\operatorname{Cov}\left[\left(\mathrm{R}_{t}-\mathrm{r}_{t}\right) \mathrm{y}_{t+1}\right]+\operatorname{Cov}\left[\left(\prod_{t}^{e}-\mathrm{E}_{t} \pi_{t+1}\right) \mathrm{y}_{t+1}\right] . \mathrm{In}$ Appendix D we show that this will be equal to:

$\operatorname{Cov}\left[\left(\mathrm{I}_{t}-\mathrm{i}_{t}\right) \mathrm{y}_{t+1}\right]=\left(\frac{k\left(1+2 \beta_{1}-n\right)}{(1+n)(1-k)}+\frac{\alpha_{1} k(1-n)^{2}}{\left(1-n^{2}\right)(1-k n)}\right) \sigma_{\varepsilon}^{2}$

This result is in line with the literature on the effect of monetary policy on future output (e.g. Bernanke \& Blinder (1992), Fuhrer \& Moore (1995)) and is essentially the consequence of the systematic 'leaning against the wind' policy described in this section. ${ }^{15}$ Even though these studies indicate that the term spread predicts future output growth, they also show that there are substantial differences between countries. For instance, Smets and Tsatsaronis (1997:4) present evidence that ' $(. .$.$) the correlation$ between annual output growth and the lagged term spread is higher in Germany than in the United States(...)'. They attribute part of this difference to the fact that the influence of inflation scares on the US nominal term spread is much more significant than in Germany as a result of the fact that the Bundesbank enjoys a higher degree of credibility. Furthermore, they present evidence that the Bundesbank reacts more vigorously in real terms to various shocks than the US. 
While inflation scares do not play a role in this model, we can investigate some factors which affect the sensitivity of the nominal term spread to current economic indicators. ${ }^{16}$ A more vigorous response of the real term spread and/or the inflation term spread to current indicator variables will lead to a stronger relationship between movements in the nominal term spread and future output. The results are summarised in the following proposition:

PROPOSITION 5: The nominal term spread $\left(\mathrm{I}_{t}-\mathrm{i}_{t}\right)$, will react more strongly to economic fundamentals, and as a result the covariance between this spread and future output $\left(\operatorname{Cov}\left[\left(\mathrm{I}_{t}-\mathrm{i}_{t}\right)\right.\right.$ $\left.\mathrm{y}_{t+1}\right]$ ) will increase if:

1. the duration of the long bond (D) increases

2. the relative weight on output stabilisation $(\lambda)$ decreases

3. the degree of output persistence $\left(\beta_{1}\right)$ increases.

\section{Proof: see Appendix E}

An increase in the duration of the long bond will induce an increase in the responsiveness of both the real term spread and the inflation term spread. While an increase in duration will not affect the long-term real rate itself, the induced decrease in policy leverage will cause the shortterm real rate $\left(\mathrm{r}_{t}\right)$ to respond more strongly to current economic fundamentals. In other words, as far as the real term spread is concerned, the increase in responsiveness to current indicators and the concomitant increase in its predictive ability with respect to future output can be entirely ascribed to 'the short end' of the (real) yield curve.

By contrast, an increase in duration will make 'the long end' of the inflation term structure $\left(\prod^{e}\right)$ less sensitive to current economic fundamentals while the one period expected rate of inflation will not be affected. Both effects will cause the nominal spread to be more responsive to economic fundamentals. The increased responsiveness of the nominal spread to inflationary shocks is also entirely responsible for the increase in the covariance between the nominal term spread and future output. This is because a change in duration will not affect the speed of disinflation. ${ }^{17}$
The practical implication of this result is that under a fully credible inflation targeting regime the duration of the debt instrument which affects aggregate demand will be one of the determinants of the response of the nominal term spread to economic developments. Because of this, the financial structure of the economy (i.e. the relative extent to which spending depends on long term interest rates) will influence the observed correlation between the term spread and future output growth. Hence, the fact that many VAR-studies (e.g. Estrella \& Mishkin, 1997 and Smets \& Tsatsaronis, 1997) indicate that the real term spread seems to be more strongly related to future output in Germany than in the US could also partly be explained by the fact that the financial structure of the German economy incorporates a larger relative share of long-term debt than the US.

Next, a larger relative weight on short-term output stabilisation $(\lambda)$ implies a more gradual path of disinflation after the economy has been hit by an inflationary shock as will be reflected in a 'flatter' inflation term structure. As for the real term structure this means that the current short-term real rate will be lower than it would have been in the presence of a smaller relative weight on output stabilisation. By contrast, since inflation will be eliminated at a lower pace, expected future short-term real rates will be higher than they would have been for a smaller value of $\lambda$. On account of these factors the real term structure will be flatter as well. Hence, the nominal term spread will be less sensitive to indicator variables and its predictive value for future output will diminish because of the fact that monetary policy will exert less influence on next period's output gap (see Endnote 15).

Finally, an increase in the degree of output persistence $\left(\beta_{1}\right)$ will increase the effect of current inflationary shocks on output in the next period and on inflation two periods into the future. To offset this effect for a given optimal target rule, (i.e. for a given planned path of disinflation), the central bank will display a more activist response to current indicator variables. This will be reflected in an increase in the responsiveness of the real term spread with respect to these indicator variables, while the inflation term spread will remain unaffected. 


\section{6}

\section{Summary and concluding remarks}

This paper incorporates the term structure of interest rates into the Svensson (1997a) inflation forecast targeting framework. We assume that aggregate demand is not directly influenced by the central bank's instrument (i.e. the one period nominal interest rate) but rather by the real yield to maturity on a long-term bond. According to the Pure Expectations Hypothesis (PEH), the nominal yield to maturity on this bond will be equal to a weighted average of expected future instrument levels where the weights are a decreasing function of time. The weights can be expressed as a function of the lifetime of the bond as measured by its duration.

Using the time-honoured Fisher decomposition, the model allows us to assess the effect of inflation targeting on the short-term interest rate, the long-term real interest rate and the long-term expected rate of inflation. An increase in the duration of the long bond will increase the responsiveness of the central bank's instrument to the current state of the economy both in nominal and in real terms. However, we also show that this will cause the nominal long-term interest rate (i.e. the interest rate which affects spending) to be less sensitive to changes in the state of the economy. This effect arises because an increase in duration will cause long-term inflationary expectations to be less volatile.

The explicit distinction between the instrument of monetary policy and the interest rate in the aggregate demand equation also turns out to be crucial when we examine the effect of a change in the central bank's relative weight on output stabilisation. If the central bank pays more attention to output fluctuations, the short-term interest rate will respond less to changes in the current indicators of future inflation. However, the effect on the long-term nominal interest rate is ambiguous. Because an inflationary shock will be eliminated more gradually, the longterm real interest rate will be less sensitive to economic fundamentals. By contrast, since it will take longer for the inflationary effect to be eliminated, the long run expected rate of inflation will become more sensitive to the current state of the economy.

The assumed transmission mechanism in this model implies a positive relationship between the nominal term spread and future output which is induced by the optimal response of monetary policy to the state of the economy. In particular, if the economy experiences a boom, both the real and the inflation term spread will be inverted. As for the first one this is because the central bank will raise the shortterm nominal interest rate to curb spending and because short-real rates are expected to fall below their current level in future. The inflation term spread reflects the central bank's desired path towards the assigned inflation target which is fully credible to the public. The positive covariance between the nominal term spread and future output arises because a tightening of monetary policy is assumed to affect output with a one-period lag. We also investigated the parameters that affect the responsiveness of the term spread to current economic fundamentals and the strength of the relationship between the term spread and future output. In general, factors that cause the short-term interest rate to become more responsive to indicator variables will also serve to increase both the sensitivity of the term spread to these variables and the correspondence between movements in the term spread and future output.

One crucial assumption in the model is that the public does not face any uncertainty about the parameters of the central bank's objective function. This means that the planned path of future expected inflation rates is fully credible. Moreover, as a result the central bank will have perfect control over the long-term real interest rate because all expected future shortterm interest rates will be pinned down by the market's expectation that the central bank will follow its optimal instrument rule in each and every future period. Since perfect control over long-term interest rates is not observed in the real world, one interesting area for possible future research would therefore be to assess the implications of uncertainty about the central bank's objective function for the term structure of interest rates. 


\section{Appendix A}

Derivation of the optimal intermediate target

This appendix provides a brief description of the derivation of the optimal intermediate target. For a more elaborate treatment see Svensson (1997a). First of all, from equation (3.1) we realise that the indirect loss function will be of the general form:

$V\left(E_{t} \pi_{t+1}\right)=\mu_{0}+\frac{1}{2} \mu\left(E_{t} \pi_{t+1}-\pi^{*}\right)^{2}$

Here, $\mu_{0}$ and $\mu$ are coefficients which remain to be determined. Next, using equation (3.1) in the main text, the first-order condition for the central bank's optimisation problem will read as follows:

$\lambda E_{t} y_{t+1}+\alpha_{1} \delta E_{t}\left(\frac{\partial V\left(E_{t+1} \pi_{t+2}\right)}{\partial E_{t+1} \pi_{t+2}}\right)=0$

Using equation (A.1) to find an expression for the partial derivative between brackets, we can write:

$E_{t} \pi_{t+2}-\pi^{*}=-\frac{\lambda}{\delta \alpha_{1} \mu} E_{t} y_{t+1}$

From equation (2.6) the conditional forecast of next period's output will be equal to:

$E y_{t+1}=\frac{1}{\alpha_{1}}\left(E_{t} \pi_{t+2}-E_{t} \pi_{t+1}\right)$

Plugging this equation into equation (A.3) and rearranging will yield equation (3.2) in the main text. Next, in order to identify the coefficients $\mu_{0}$ and $\mu$ in equation (A.1) we realise that using equation (3.1) we can compute:

$\frac{\partial V\left(E_{t} \pi_{t+1}\right)}{\partial E_{t} \pi_{t+1}}=E_{t} \pi_{t+1}-\pi^{*}+\delta E_{t}\left\{\frac{\partial V\left(E_{t+1} \pi_{t+2}\right)}{\partial E_{t+1} \pi_{t+2}} \frac{\partial E_{t+1} \pi_{t+2}}{\partial E_{t+1} \pi_{t+1}}\right\}$

As far as this equation is concerned we note that from equations (A.1) and (2.4) respectively, we can derive:

$\frac{\partial V\left(E_{t+1} \pi_{t+2}\right)}{\partial E_{t+1} \pi_{t+2}}=\mu\left(E_{t+1} \pi_{t+2}-\pi^{*}\right)$

$\frac{\partial E_{t+1} \pi_{t+2}}{\partial E_{t+1} \pi_{t+1}}=1$

Plugging these equations into (A.5) and using the expression obtained for $\left(E_{t} \pi_{t+2}-\pi^{*}\right)$ in equation (3.2) we can rewrite (A.5) as follows:

$$
\frac{\partial V\left(E_{t} \pi_{t+1}\right)}{\partial E_{t} \pi_{t+1}}=\left[1+\frac{\lambda \delta \mu}{\delta \alpha_{1}^{2} \mu+\lambda}\right]\left(E_{t} \pi_{t+1}-\pi^{*}\right)
$$

Identification for the coefficient for $\left(E_{t} \pi_{t+1}-\pi^{*}\right)$ yields:

$\mu=\left[1+\frac{\lambda \delta \mu}{\delta \alpha_{1}^{2} \mu+\lambda}\right] \equiv F(\mu)$

From this equation it can be seen that for $\mu \in[0, \infty)$ it will hold that $F(\mu) \in\left[1, \lambda / \alpha^{2}\right)$. Using this it can be shown that the unique positive solution for $\mu$ will be:

$\mu=\frac{1}{2}\left(1-\frac{\lambda(1-\delta)}{\delta \alpha_{1}^{2}}+\sqrt{\left(1+\frac{\lambda(1-\delta)}{\delta \alpha_{1}^{2}}\right)^{2}+\frac{4 \lambda}{\alpha_{1}^{2}}}\right) \geq 1$

To prove that $\partial n / \partial \lambda>0$ we first realise that we can write:

$n=\frac{1}{\delta \alpha_{1}^{2} \frac{\mu}{\lambda}+1} ; \quad \frac{\partial n}{\partial(\mu / \lambda)}=-\frac{\delta \alpha_{1}^{2}}{\left(\delta \alpha_{1}^{2} \frac{\mu}{\lambda}+1\right)^{2}}<0$ 
Furthermore, using equation (A.9) we can compute:

$\frac{\partial\left(\frac{\mu}{\lambda}\right)}{\partial \lambda}=\frac{1}{2}\left\{\frac{\frac{-4}{\alpha_{1}^{2} \lambda^{2}}-2\left(\frac{\frac{(1-\delta)}{\alpha_{1}^{2} \delta}+\frac{1}{\lambda}}{\lambda^{2}}\right)}{\sqrt[2]{\left(\frac{(1-\delta)}{\alpha_{1}^{2} \delta}+\frac{1}{\lambda}\right)^{2}+\frac{4}{\alpha_{1}^{2} \lambda}}} \frac{1}{\lambda^{2}}\right\}<0$

Consequently, it will hold that: $\partial n / \partial \lambda=\partial n / \partial(\mu / \lambda) * \partial(\mu / \lambda) / \partial \lambda>0$.

\section{Appendix B}

Derivation of the long real rate under the optimal monetary policy rule

Leading equation (2.6) by one period, using equation (2.6) in the resulting expression, taking expectations conditional on the information in period $t$ and rearranging we obtain:

$E_{t} R_{t+1}=\beta_{1}^{2} y_{t}-E_{t} y_{t+2}-\beta_{1} R_{t}+\beta_{2}\left(\beta_{1}+\beta_{2}\right) x_{t}$

Furthermore, by leading equation (2.5) one period and taking expectations conditional on the information in period $t, E y_{t+2}$ can be expressed as follows:

$E_{t} y_{t+2}=\frac{1}{\alpha_{1}}\left[E_{t} \pi_{t+3}-E_{t} \pi_{t+2}\right]$

Since the central bank will follow its optimal target rule in every period we can find an expression for the term between brackets by leading equation (3.2) one period and subtracting equation (3.2) from the result:

$E_{t} \pi_{t+3}-E_{t} \pi_{t+2}=-n(1-n)\left[E_{t} \pi_{t+1}-\pi^{*}\right]$

Using equations (B.2) and (B.3) we can rewrite (B.1) as follows:

$E_{t} R_{t+1}=\frac{n(1-n)}{\alpha_{1}}\left(\pi_{t}-\pi^{*}\right)+\left(n(1-n)+\beta_{1}^{2}\right) y_{t}+\beta_{2}\left(\beta_{1}+\beta_{2}\right) x_{t}-\beta_{1} R_{t}$

Casting the expression for $\mathrm{R}_{t}$ obtained in equation (2.4) in its first-order equivalence (see equation (2.2)) and substituting (B.4) in the resulting expression yields:

$R_{t}=\frac{1-k}{1+k \beta_{1}} n_{t}+\frac{k n(1-n)}{\alpha_{1}\left(1+k \beta_{1}\right)}\left(\pi_{t}-\pi^{*}\right)+\frac{k\left(n(1-n)+\beta_{1}^{2}\right)}{1+k \beta_{1}} y_{t}+\frac{k \beta_{2}\left(\beta_{1}+\beta_{2}\right)}{1+k \beta_{t}} x_{t}$

Substituting this expression into equation (3.3) using the fact that $r_{t}=i_{t}-\pi_{t}-\alpha_{1} y_{t}$ will yield equation (3.4) in the main text.

\section{Appendix C}

Derivation of the long-term expected inflation rate

Repeated substitution using equation (3.2) yields:

$E_{t} \pi_{t+i}=\pi^{*}+n^{i-1}\left[E_{t} \pi_{t+1}-\pi^{*}\right]$

Using this in equation (2.4) we have:

$\prod_{t}^{e}=(1-k)\left[E_{t} \pi_{t+1}+k\left(\pi^{*}+n\left(E_{t} \pi_{t+1}-\pi^{*}\right)\right)+k^{2}\left(\pi^{*}+n^{2}\left(E_{t} \pi_{t+1}-\pi^{*}\right)\right)+\ldots ..\right]$ 
Solving for the infinite summation and rearranging this can be rewritten as follows:

$\prod_{t}^{e}=\pi^{*}+\frac{(1-k)}{(1-k n)}\left[E_{t} \pi_{t+1}-\pi^{*}\right]$

Using the fact that $E_{t} \pi_{t+1}=\pi_{t}+\alpha_{1} y_{t}$ we obtain equation (4.2) in the main text.

\section{Appendix D}

Derivation of the covariance between the real and the inflation term spread and future output

Plugging the equilibrium solution for $\mathrm{R}_{t}$ obtained in equation (4.1) into the dynamic equation for output (2.6) and subtracting $\pi^{*}$ on both sides of the Phillips-curve relationship (2.5), we have the following two-dimensional VAR (1) system:

$Z_{t+1}=A Z_{t}+\phi_{t+1}$

where:

$Z_{t}=\left[\begin{array}{c}y_{t} \\ \pi_{t}-\pi^{*}\end{array}\right] ; A=\left[\begin{array}{cc}-(1-n)^{-\frac{(1-n)}{\alpha_{1}}} \\ \alpha_{1}\end{array}\right] ; \phi_{t+1}=\left[\begin{array}{c}\varepsilon_{t+1} \\ 0\end{array}\right]$

The system has two distinct and real Eigenvalues: $\mathrm{e}_{1}=0$ and $\mathrm{e}_{2}=\mathrm{n}$, which indicate that the system is stationary provided $\mathrm{n}$ is strictly smaller than one (implying a finite value of $\lambda$ ). Let $\operatorname{vec}(\Phi)=\left(\sigma_{\varepsilon}^{2} 0000\right)^{\psi}$ be the vector form of the variance-covariance matrix of $\phi$ and let $\operatorname{vec}(V)=\left(\sigma_{y}^{2} \sigma_{\pi y} \sigma_{\pi y} \sigma_{\pi}^{2}\right)^{\psi}$ be the vector form of the variance-covariance matrix of Z. Assuming $0 \leq \mathrm{n}<1$ we can compute:

$\operatorname{vec}(V)=(I-A \otimes A)^{-1} \operatorname{vec}() \Rightarrow \operatorname{vec}(V)=\left[\begin{array}{c}\frac{2 \sigma_{\varepsilon}^{2}}{(1+n)} \\ \frac{-\alpha_{1} \sigma_{\varepsilon}^{2}}{(1+n)} \\ \frac{-\alpha_{1} \sigma_{\varepsilon}^{2}}{(1+n)} \\ \frac{\alpha_{1}^{2} \sigma_{\varepsilon}^{2}}{\left(1-n^{2}\right)}\end{array}\right]$

From this equation it can be seen that: $\partial \sigma_{y}^{2} / \partial n<0, \partial \sigma_{\pi y} / \partial n<0$ and $\partial \sigma_{\pi}^{2} / \partial n>0$, i.e. $\lambda$ (and therefore $n$ ) affects the trade-off between inflation variability and output variability.

The expression for $\operatorname{Cov}\left[\left(\mathrm{R}_{t}-\mathrm{r}_{t}\right) \mathrm{y}_{t+1}\right]$ can be obtained as follows: First of all, we compute the product of the expression for $\mathrm{y}_{t+1}$ found in equation (D.1) and the real term spread in equation (5.1). Subsequently, we take the unconditional expectation of the resulting expression where we use the fact that: $E\left(\pi_{t}-\pi^{*}\right)^{2}=\sigma_{\pi}^{2}, E\left(y_{t}^{2}\right)=\sigma_{y}^{2}$ and $E\left(\left(\pi_{t}-\pi^{*}\right) y_{t}\right)=\sigma_{\pi y}$ and the fact that $\varepsilon_{t+1}$ is exogenous with respect to $\left(\pi_{t}-\pi^{*}\right)$ and $y_{t}$. Similarly, $\operatorname{Cov}\left[\left(\prod_{t}^{e}-E_{t} \pi_{t+1}\right) y_{t+1}\right]$ can be found by computing the product of equation (5.2) and the afore-mentioned expression for $y_{t+1}$. The summation of these two expressions then yields equation (4.4) in the main text. 


\section{Appendix E}

Proofs of propositions ${ }^{18}$

\section{PROPOSITION 1}

Define

$a_{0}=1+\frac{(1-n)\left(1+k \beta_{1}-k n\right)}{\alpha_{1}(1-k)} \quad a_{1}=\frac{\left(1+\beta_{1}-n\right)\left(1+k \beta_{1}\right)+\alpha_{1}(1-k)-k\left(n(1-n)+\beta_{1}^{2}\right)}{(1-k)}$

$a_{3}=\frac{\beta_{2}\left(1-k \beta_{2}\right)}{(1-k)}$

Then it can be shown that

$\frac{\partial a_{0}}{\partial k}=\frac{(1-n)\left(1+\beta_{1}-n\right)}{\alpha_{1}(k-1)^{2}}>0 ; \frac{\partial a_{1}}{\partial k}=\frac{(n-1)^{2}+\beta_{1}(2-n)}{(k-1)^{2}}>0$

$\frac{\partial a_{3}}{\partial k}=\frac{\beta_{2}\left(1-\beta_{2}\right)}{(k-1)^{2}}>0$

Since it holds that $\partial \mathrm{k} / \partial \mathrm{D}=1 /(1+\mathrm{D})^{2}>0$ it follows that $\partial \mathrm{a}_{i} / \partial \mathrm{D}>0$ for $i=0,1,2$

Next, as far as the parameter $n$ is concerned, we can compute: ${ }^{19}$

$\frac{\partial a_{0}}{\partial n}=-\frac{1+k\left(1+\beta_{1}-2 n\right)}{\alpha_{1}(1-k)}<0 ; \frac{\partial a_{1}}{\partial n}=-\frac{1+k\left(1+\beta_{1}-2 n\right)}{(1-k)}<0$

In Appendix $\mathrm{A}$ it is shown that $\partial \mathrm{n} / \partial \lambda>0$. Therefore, we can conclude: $\partial \mathrm{a}_{0} / \partial \lambda<0$ and $\partial \mathrm{a}_{1} / \partial \lambda<0$.

Finally, we can show:

$\frac{\partial a_{0}}{\partial \beta_{1}}=\frac{k(1-n)}{\alpha_{1}(1-k)}>0 ; \frac{\partial a_{1}}{\partial \beta_{1}}=\frac{1+k(1-n)}{(1-k)}>0$

\section{PROPOSITION 3}

\section{Define}

$b_{0}=\frac{(1-k)}{(1-k n)} ; b_{1}=\frac{\alpha_{1}(1-k)}{(1-k n)}$

Then it can be shown that:

$\frac{\partial b_{0}}{\partial k}=-\frac{(1-n)}{(1-k n)^{2}}<0 ; \frac{\partial b_{0}}{\partial n}=\frac{k(1-k)}{(1-k n)^{2}}>0$
$\frac{\partial b_{1}}{\partial k}=-\frac{\alpha_{1}(1-n)}{(1-k n)^{2}}<0 ; \frac{\partial b_{1}}{\partial n}=\frac{\alpha_{1} k(1-k)}{(1-k n)^{2}}>0$

The proof then follows from the fact that $\partial \mathrm{k} / \partial \mathrm{D}>0$ and $\partial \mathrm{n} / \partial \lambda>0$.

\section{PROPOSITION 4}

As for equation (5.1), the coefficient for $\left(\pi_{t}-\pi^{*}\right)$ will be smaller than or equal to zero since $0 \leq \mathrm{n}<1$. Next, for the coefficient for $\mathrm{y}_{t}$ to be negative, the denominator of this coefficient needs to be positive, which will be the case since this condition can be rewritten as follows:

$\beta_{1}(2-n)>-1-n^{2}+2 \mathrm{n} \quad \Leftrightarrow \quad \beta_{1}>\frac{-(n-1)^{2}}{(2-n)}$

In equation (5.2) noting that both $k$ an $n$ are restricted to lie within the unit interval is obvious proof of this. Since the proof holds for the real and inflation term spread it must also hold for the nominal term spread. 


\section{PROPOSITION 5}

As far as equation (5.1) is concerned define:

$c_{0}=\frac{k(1-n)\left(1+\beta_{1}-n\right)}{\alpha_{1}(1-k)} ; c_{1}=\frac{k\left[1+2 \beta_{1}+n\left(n-\left(2+\beta_{1}\right)\right)\right]}{(1-k)}$

Then it can be shown that: ${ }^{20}$

$\frac{\partial c_{0}}{\partial k}=\frac{(1-n)\left(1+\beta_{1}-n\right)}{\alpha_{1}(k-1)^{2}}>0 ; \frac{\partial c_{0}}{\partial n}=-\frac{k\left(2(1-n)+\beta_{1}\right)}{\alpha_{1}(1-k)}<0$

$\frac{\partial c_{1}}{\partial k}=\frac{1+2 \beta_{1}+n\left(n-\left(2+\beta_{1}\right)\right)}{(k-1)^{2}}>0 ; \frac{\partial c_{1}}{\partial n}=-\frac{k\left(2(1-n)+\beta_{1}\right)}{(1-k)}<0$

$\frac{\partial c_{0}}{\partial \beta_{1}}=\frac{k(1-n)}{\alpha_{1}(1-k)}>0 ; \frac{\partial c_{1}}{\partial \beta_{1}}=-\frac{k(2-n)}{(1-k)}>0$

Since it is shown in Appendix A that $\partial \mathrm{n} / \partial \lambda>0$, we conclude that $\partial \mathrm{c}_{i} / \partial \lambda<0$ for $\mathrm{i}=0,1$. Similarly, since $\partial \mathrm{D} / \partial \mathrm{k}>0$ it will hold that $\partial \mathrm{c}_{i} / \partial \mathrm{D}>0$ for $i=0,1$.

Next, as far as equation (5.2) is concerned, define:

$d_{0}=\frac{k(1-n)}{(1-k n)} ; d_{1}=\frac{\alpha_{1} k(1-n)}{(1-k n)}=\alpha_{1} d_{0}$

Then we can compute:

$\frac{\partial d_{0}}{\partial k}=\frac{1-n}{1-k n}>0 ; \frac{\partial d_{0}}{\partial n}=-\frac{k}{1-k n}<0$

Here we realise that $\partial \mathrm{d}_{1} / \partial \mathrm{k}=\alpha_{1} \partial \mathrm{d}_{0} / \partial \mathrm{k}$ and $\partial \mathrm{d}_{1} / \partial \mathrm{n}=\alpha_{1} \partial \mathrm{d}_{0} / \partial \mathrm{n}$.

Next, using equation (5.3) we can compute:

$\frac{\partial \operatorname{Cov}\left[\left(R_{t}-r_{t}\right) y_{t+1}\right]}{\partial k}=\frac{\left(1+2 \beta_{1}-n\right) \sigma_{\varepsilon}^{2}}{(k-1)^{2}(1+n)}>0 ; \frac{\partial \operatorname{Cov}\left[\left(R_{t}-r_{t}\right) y_{t+1}\right]}{\partial \beta_{1}}=\frac{2 k \sigma_{\varepsilon}^{2}}{(1-k)(1+n)}>0$

$\frac{\partial \operatorname{Cov}\left[\left(R_{t}-r_{t}\right) y_{t+1}\right]}{\partial n}=-\frac{2 k\left(1+\beta_{1}\right) \sigma_{\varepsilon}^{2}}{(1-k)\left(1+n^{2}\right)}<0$ 


\section{Endnotes}

1 The use of explicit inflation targets derives its theoretical rationale from the fact that they can be used to overcome credibility problems since they can mimic the results of optimal performance incentive contracts (see Walsh, 1995 and Svensson, 1997b). For an analysis that looks at the implications of preference uncertainty for the equivalence of linear Walsh (1995) contracts and (quadratic) Svensson (1997b) inflation targets, see Schaling, Hoeberichts \& Eijffinger (1998) However, these theories assume that central banks can instantaneously choose the rate of inflation.

2 For example, in March 2009 the South African Reserve Bank (SARB) continued to drain significant amounts of liquidity out of the local money market in order to force commercial banks to borrow at the official repo rate.

3 Bernanke \& Woodford (1997) have argued that inflation forecast targeting can only work if the inflation forecast is based on the central bank's own structural model of the economy. They show that responding to private sector forecasts may lead to indeterminacy or non-existence of a rational expectations equilibrium. This claim was later refuted by Evans \& Honkapohja (2003).

4 For an extension of the Svensson (1997a) model with a nonlinear (convex) Phillips curve, see Schaling (2004).

5 The concept of duration allows for a comparison between the holding period returns on discount bonds and coupon bonds. The duration of a discount bond is equal to its maturity. Because a coupon bond can be seen as a package of discount bonds each of which has a different maturity, its duration, which is intended to be a measure of the length of time an investor invests his money, will be a weighted average of the maturities of the underlying discount bonds. The weight on each maturity is then the present value of the discount bond using the coupon bond's yield to maturity as the discount rate.

6 This equation can either be seen as representing a situation of purely backward-looking expectations or as a reduced form of the following equation: $\pi_{t+1}=(1-\theta) E_{t} \pi_{t+1}+\theta \pi_{t}+\omega y_{t}$ in which case it holds that $\alpha_{1}=\omega / \theta$. Note that the latter equation has some similarities with the so-called hybrid New-Keynesian Phillips curve (see Woodford, 2003). The standard NK Phillips curve reads (see e.g. Bullard \& Schaling, 2006): $\pi_{t}=\delta \hat{E}_{t} \pi_{t+1}+\alpha_{1} y_{t}$ Here the slope of the Phillips curve is no longer a free ad hoc parameter, but we have the structural interpretation: $\alpha_{1}=\sigma[(1-\theta)(1-\delta \theta)] / \theta$. Here $\theta$ indicates the probability that a firm will not be able to change its price today, and $\sigma$ is a parameter controlling the curvature in preferences over consumption (Woodford, 2003: 187). The hat sign ' $\wedge$ ' denotes a possibly non-rational private sector expectation.

7 Of course, there will be many interest rates which pertain to debt instruments of both short and long maturities which affect aggregate demand. In this respect, the parameter $\mathrm{D}$ can be seen as an indicator of the relative share of long-term private debt in the economy.

8 As noted by Svensson (1997b, 1997a) this means that the central bank does have a long run inflation target $\left(\pi^{*}\right)$ but no long run output target (other than the natural rate of output). In other words, even though the central bank wishes to limit shortterm output variability, in the long run its only objective is price stability.

9 For a discussion of the relative merits of dynamic programming and the Lagrange method see Schaling (2001). For applications of the latter to a non-linear optimisation problem, and a regime switching model see Schaling (2004) and Bullard \& Schaling (2001), respectively.

10 Of course the expectations will be formed by the private sector. However, we do not have to take this into account explicitly since there is no information asymmetry in the model.

11 It may be argued that this is not in line with reality. It is, however, the logical implication of the present framework in which the public believes that the central bank will always react predictably and optimally to economic shocks. This suggests that uncertainty about the preferences of the central bank may be one of the reasons for imperfect control over the long-term real rate interest rate. By this we mean imperfect control at any given moment in time. Of course, even if it had perfect control, the central bank would not be able to engineer a systematic deviation of the actual long-term real rate from the equilibrium long-term real rate determined by such factors as thrift and productivity. In our model the latter is assumed to be constant and is normalised to zero. (see Footnote 12).

12 Note that if instead of (3.5) the central bank would follow the more general instrument rule $r_{t}=\varphi_{\pi} \pi_{t}+$ $\varphi_{y} y_{t}+\varphi_{r} E_{t} R_{t+1}$ one would obtain the following firstorder stochastic difference equation for the long real rate $R_{t}=\alpha_{2} E_{t} R_{t+1}+x_{t}$, where $\alpha_{2} \equiv \varphi_{r}(1-k)+k$ and $x_{t} \equiv(1-k)\left[\varphi_{\pi} \pi_{t}+\varphi_{y} y_{t}\right]$. Thus, depending on the size and sign of $\varphi_{r}$ we have a potential 
indeterminate rational expectations equilibrium. More precisely, if and only if $\left|\alpha_{2}\right|<1$ will the equilibrium be unique. As it turns out this condition is satisfied for the rule (3.5).

13 In that case we obtain: $i_{t}=\pi_{\mathrm{t}}+\left[(1-\mathrm{n}) / \alpha_{1}\right]\left(\pi_{\mathrm{t}}-\pi^{*}\right)$ $+\left(1+\beta_{1}+\alpha_{1}-\mathrm{n}\right) y_{t}+\beta_{2} \times \mathrm{t}$ which can easily be shown to be the solution to a particular variant of this model where it holds that $\mathrm{R}_{t}=\mathrm{r}$.

14 In the steady state it holds that $\pi_{t}=\pi^{*}$ and $\mathrm{y}_{t}=0$. This implies that the steady state values of both the short-term and the long-term real rates are zero and the steady state values of both the one-period and long-term expected rate of inflation are equal to $\pi^{*}$.

15 Since in our model this predictive ability is induced by monetary policy it follows that the central bank cannot base its policy on this predictive ability. In reality, probably both monetary and non-monetary factors influence this relationship but even then the central bank will have to give a structural interpretation to movements in the yield curve. Indeed, following an instrument rule of the form $\mathrm{i}_{t}=\chi\left(\mathrm{I}_{t}-\mathrm{i}_{t}\right)$ as proposed by McCallum (1994) may lead to multiple equilibria (see Bernanke \& Woodford, 1997, Evans \& Honkapohja, 2003 and Tesfaselassie, Schaling \& Eijffinger, 2006).

16 Since the central bank is credibly committed to the loss function, the path of expected future inflation is unambiguously tied down by the optimal targeting rule (3.2).

17 In Appendix D it is shown that optimal monetary policy will yield the following reduced form dynamic equation for output: $\mathrm{y}_{t+1}=-(1-\mathrm{n}) \mathrm{y}_{t}-$ $\left((1-\mathrm{n}) / \alpha_{1}\right)\left(\pi_{t}-\pi^{*}\right)+\varepsilon_{t+1}$. Consequently, the effect of current monetary policy on future output is fully captured by the parameter $n$ in the optimal targeting rule (3.2).

18 The proof pertains to the reaction coefficients of it. However, since $\mathrm{r}_{t}=\mathrm{i}_{t}-\mathrm{E}_{t} \pi_{t+1}$ and since the one period expected inflation rate is predetermined the results carry over to the reaction coefficients of $r_{t}$.

19 Note that the inequality $1+\mathrm{k}\left(1+\beta_{1}-2 \mathrm{n}\right)>0$ can be rewritten as $\beta_{1}>2 n-(1 / k)-1$. The RHS of this expression is strictly increasing in both $k$ and $n$. Since in addition it holds that $0 \leq k \leq 1$ and $0 \leq n \leq 1$, we know the inequality will always be satisfied if it holds for the specials case in which $k=n=1$. Substituting this into the inequality yields: $\beta_{1}>0$.

20 Note that it holds that: $0 \leq k \leq 1 ; 0 \leq n \leq 1$; $0<\beta_{2}<1$ and that the proof that the denominator in the expression for $\partial \mathrm{a}_{1} / \partial \mathrm{k}$ is greater than zero is given in the proof of PROPOSITION 2.

\section{References}

BERNANKE, B. \& BLINDER, A., 1992. The federal funds rate and the channels of monetary transmission, American Economic Review, 82: 901-921. BERNANKE, B. \& WOODFORD, M., 1997. Inflation forecasts and monetary policy. NBER Working Paper no. 6157.

BULLARD, J. \& SCHALING, E., 2001. New

economy-new policy rules? Federal Reserve Bank of St. Louis Review, 83(5): 57-66.

BULLARD, J. \& SCHALING, E., 2006. Monetary policy, determinacy and learnability in the open economy. European Central Bank Working Paper, No 611, April.

ESTRELLA, A. \& MISHKIN, F., 1997. The predictive power of the term structure of interest rates in Europe and the United States: implications for the European Central Bank, European Economic Review, 41(7): 1357-1402.

EVANS, G. \& HONKAPOHJA, S., 2003. Expectations and the stability problem for optimal monetary policies. Review of Economic Studies, 70: 807-824. FUHRER, J., 1996. Monetary policy shifts and longterm interest rates. Quarterly Journal of Economics, 1183-1209.

FUHRER, J. \& MOORE, G., 1995. Monetary policy trade-offs and the correlation between nominal interest rates and real output. American Economic Review, 85: 219-239.

JOYCE, M., LILDHOLDT, P. \& SORENSEN, S., 2009. Extracting inflation expectations and inflation risk premia from the term structure: a joint model of the UK nominal and real yield curves. Bank of England Working Paper No. 360, February.

MCCALLUM, B., 1994. Monetary policy and the term structure of interest rates, NBER Working Paper no. 4938.

MCGOUGH, B., RUDEBUSCH, G. \& WILLIAMS,

J., 2005. Using a long-term interest rate as the monetary policy instrument, Journal of Monetary Economics, 52: 855-879.

RUDEBUSCH, G., 1995. Federal reserve interest rate targeting, rational expectations and the term structure, Journal of Monetary Economics 35(2): 245-274.

SCHALING, E., HOEBERICHTS, M. \&

EIJFFINGER, S., 1998. Incentive contracts for central bankers under uncertainty: Walsh-Svensson nonequivalence revisited. Discussion Paper CentER for Economic Research, 9811, February. SCHALING, E., 2001. Dynamic programming versus Lagrange: Is there a horse race in dynamic optimization? in Klok, H, T van Schaik and $\mathrm{S}$ Smulders (Eds). Economologues - Liber Amicorum 
for Theo van de Klundert, Tilburg University Press: 334-349.

SCHALING, E., 2004. The nonlinear Phillips Curve and inflation forecast targeting: symmetric vs. asymmetric monetary policy rules, Journal of Money, Credit and Banking, 36(3) Part 1: 361-386.

SHILLER, R., 1979. The volatility of long-term interest rates and expectations theories of the term structure, Journal of Political Economy, 87(6): 11901219.

SHILLER, R., CAMPBELL, J. \& SCHOEHOLTZ, K., 1983. Forward rates and future policy: interpreting the term structure of interest rates, Brookings Papers on Economic Activity, 1: 173-217.

SCHALING, E., HOEBERICHTS, M. \&

EIJFFINGER, S., 1998. Incentive contracts for central bankers under uncertainty: Walsh-Svensson nonequivalence revisited, Discussion Paper CentER for Economic Research, 9811 (February).

SHILLER, R., CAMPBELL, J. \& SCHOEHOLTZ, K., 1983. Forward rates and future policy: interpreting the term structure of interest rates, Brookings Papers on Economic Activity 1: 173-217.

SMETS, F. \& TSATSARONIS, K., 1997. Why does the yield curve predict economic activity? Dissecting evidence for Germany and the United States, BIS Working Papers, No. 49.

SVENSSON, L., 1997a. Optimal inflation targets, 'conservative' central banks and linear inflation contract, American Economic Review, 87: 98-114. SVENSSON, L., 1997b, 1997a. Inflation forecast targeting: implementing and monitoring inflation targets, European Economic Review, 41: 1111-46. SVENSSON, L., 1997b. Optimal inflation targets, 'conservative' central banks and linear inflation contract, American Economic Review, 87: 98-114. TAYLOR, J., 1993. Discretion versus policy rules in practice, Carnegie-Rochester Conference Series on Public Policy, 39: 195-214.

TESFASELASSIE, M., SCHALING, E. \& EIJFFINGER, S., 2006. Learning about the term structure and optimal rules for inflation targeting, CEPR Discussion Paper, No. 5896, October.

TURNOVSKY, S., 1989. The term structure of interest rates and the effects of macroeconomic policy, Journal of Money, Credit and Banking, 21(3): 321-347. WALSH, C., 1995. Optimal contracts for central bankers. American Economic Review, 85: 150-167. WOODFORD, M., 2003. Interest and prices, Princeton University Press. 